\title{
Aus dem Vorwort zur ersten Auflage.
}

In der Arbeit, die ich hiermit den Fachgenossen vorlegen möchte, habe ich den Versuch gemacht, eine Frage, die bis jetzt fast ausschlieBlich auf medizinischem Gebiete diskutiert worden ist, auf dem umfassenderen Boden der ethnischen Psychologie nachzuprüfen. Der Schwierigkeiten, welche ein solcher Versuch bieten muBte, war ich mir wohl bewußt und ich zweifle nicht daran, daB die Beurteilung, die er erfahren wird, eine sehr verschiedenartige sein wird. Einige werden kurzweg sagen, „das ist nicht wahr", andere werden behaupten, das sei einfach eine neue Umschreibung für alte und längst bekannte Dinge, von dritter Seite ist wohl auch ein lautes oder leises „Anathema sit“ zu gewärtigen. Das alles ist, da es den wahren 'Tatbestand nicht ändern wird, vollkommen gleichgültig: der ausschlieBliche Zweck, den ich mit meiner Arbeit verfolgte, war der, die Aufmerksamkeit der Ethnologen auf eine Kategorie von psychologischen Erscheinungen zu lenken, die bis jetzt auf ethnologischem Gebiete sozusagen keine Beachtung gefunden haben, trotzdem sie den einzigen Schlüssel für das Verständnis mancher Dinge enthalten, welche bis jetzt als zusammenhanglose und unverständliche, weil unverstandene, Mosaik die ethnologischen Lehrbücher füllen.

Eine Änderung dieses Verhältnisses ist erst dann zu erhoffen, wenn die Ethnologie die ihr ihrem Wesen nach gebührende Selbstständigkeit und die ihrer allgemeinen Wichtigkeit als Bildungsmittel höheren Ranges entsprechende Stellung im Rahmen der an Hochschulen gelehrten Disziplinen erlangt haben wird. Die erste und unerläBlichste Bedingung zur Erreichung dieses Zieles ist aber die durchgreifende Trennung der Ethnologie von der Geographie, in 
deren Fahrwasser sie sich, soweit es sich um ihre Pflege an den Universitäten handelt, vorwiegend gehalten hat und zwar keineswegs zu ihrem Vorteil. Niemand wird die zahlreichen Berührungspunkte und die vielfache Anregung in Abrede stellen, welche die beiden Disziplinen gegenseitig gewinnen können. Die essentielle Grundlage der Ethnologie aber ist die psychologische, und erst wenn diese einmal fest ausgelegt sein wird, können die geographischen Faktoren, als ein Element sekundärer Natur, vielen anderen höchstens gleichwertig, in ihrer Wirkungsweise klar beurteilt werden. Die reiche Fülle neuer, fruchtbarer Gedanken und weitausschauender Gesichtspunkte, welche wir RATZEL und der von ihm inaugurierten ,geographischen" Betrachtungsweise der ethnologischen Erscheinungen verdanken, wird, wenn ich meine bescheidene Meinung äußern darf, erst dann an die richtige Stelle rücken können, wenn die völkerpsychologische Betrachtung vorausgegangen und zu einer festgegründeten Disziplin, der psychischen Anthropologie geworden ist.

Viel enger als an die Geographie, ist die Ethnologie durch Inhalt und Forschungsmethode an andere Disziplinen gebunden: an die Medizin, die Volkswirtschaftslehre, die Linguistik, die Geschichte, und was der Ethnologie noch hauptsächlich mangelt, ist die Vertiefung nach den aus diesen Wissenszweigen entlehnten Grundsätzen der wissenschaftlichen Analyse. Wie vollständig unabhängig von den "geographischen" Faktoren breite und grundlegende Kategorien völker-psychologischer Erscheinungen sich gestalten und wie vollkommen gleichartig sie sich andererseits als Reaktion auf identische Reize unter den allerverschiedensten äußeren Bedingungen abspielen, soll in der vorliegenden Untersuchung gezeigt werden.

Mag also immerhin die Geographie für ihre Zwecke auch ihre eigene Behandlungsweise ethnographischer Erscheinungen beibehalten, so wird die Ethnologie doch stets den Anspruch auf wissenschaftliche Selbständigkeit und völlige Unabhängigkeit von der geographischen Betrachtungsweise erheben müssen. Und wenn sie sich nicht bloB in die Fläche, sondern auch in die Tiefe ausgestalten will, so wird ihre Grundlage die psychologische Betrachtung des normalen und, wie die vergleichende Ethnologie der Religionen zeigt, $\mathrm{zu}$ einem nicht geringen Teile auch des pathologischen Menschen sein und bleiben müssen. Und zwar darf diese Betrachtung ihre Quellen nicht bloB im Studium des literarischen Materials und nicht bloB in der Beobachtung überseeischer "Naturvölker“ erblicken, 
sondern sie muß selbst im Menschen der allernächsten Umgebung ein ethnologisches Objekt sehen, aus welchem in unablässiger Bemühung durch direkte Beobachtung und Befragung ein reiches und durch seine Zuverlässigkeit und Kontrollierbarkeit besonders wertvolles Material zu gewinnen ist, das erst das richtige Verständnis fremdländischer Erscheinungen vermittelt.

Küsnacht bei Zürich, 1. Mai 1894.

\section{Otto Stoll.}

\section{Vorwort zur zweiten Auflage.}

Wenn auch Grundplan und Grundgedanke des Buches dieselben geblieben sind, wie bei der ersten Auflage, so haben bei der vorliegenden zweiten Auflage doch eine Reihe von Änderungen, die, wie ich hoffe, Verbesserungen sind, Platz gegriffen. Nicht nur sind mehrere, für das Verständnis der suggestiven Wirkungen auf dem Gebiete der Völkerpsychologie sehr wichtige Partien ganz neu hinzugekommen, wie z. B. der Abschnitt über die französische Revolution, sondern einzelne Tatsachengruppen sind gegenüber der früheren Auflage auch in dem Sinne umgearbeitet worden, daß die geschilderten psychischen Erscheinungen eingehend analysiert wurden, um das suggestive Element klarer hervortreten zu lassen. Ich habe damit einem mir von befreundeter Seite mehrfach geäußerten Wunsche Rechnung zu tragen versucht. Von verschiedener Seite war mir auch darüber geklagt worden, da $B$ die erste Auflage die Zitate aus fremdsprachigen Werken in der Originalsprache brachte. Ich habe daher diesmal alle fremdsprachigen Zitate entweder selbst übersetzt oder, wo nötig, deutschen Übersetzungen entnommen, die im Text oder im Literaturverzeichnis namhaft gemacht sind. Ich hoffte auch damit die Lektüre des Buches leichter und flüssiger und die Verständlichkeit allgemeiner zu machen, als es bei der häufigen Unterbrechung des Textes durch fremdsprachige Zitate möglich war. 